\title{
Effects of Auto-Servo Ventilation on Patients with Sleep-Disordered Breathing, Stable Systolic Heart Failure and Concomitant Diastolic Dysfunction: Subanalysis of a Randomized Controlled Trial
}

\author{
Christoph Birner $^{\mathrm{a}} \quad$ Frederic Series $^{\mathrm{d}}$ Keir Lewis $^{\mathrm{e}}$ Amit Benjamin $^{\mathrm{e}}$ \\ Silke Wunderlich ${ }^{a}$ Pierre Escourrou ${ }^{f}$ Florian Zeman $^{b}$ Ruth Luigart ${ }^{a}$ \\ Michael Pfeifer ${ }^{a, c}$ Michael Arzt ${ }^{a}$ \\ a Division of Respirology, Department of Internal Medicine II and ${ }^{b}$ Center for Clinical Studies, University Hospital \\ Regensburg, Regensburg, and ${ }^{\mathrm{C} C e n t e r}$ for Pneumology, Donaustauf Hospital, Donaustauf, Germany; ${ }^{\mathrm{d} C e n t r e}$ de \\ Recherche, IUCPQ, Université Laval, Quebec, Qué., Canada; ${ }^{e}$ Department of Respiratory Medicine, Prince Philip \\ Hospital and Swansea College of Medicine, Llanelli, UK; ${ }^{f}$ Centre de Médecine du Sommeil, Hôpital Antoine Béclère, \\ Clamart, France
}

\section{Key Words}

Auto-servo ventilation - Diastolic dysfunction - Heart failure . Sleep apnea $\cdot$ Sleep-disordered breathing

\begin{abstract}
Background: Systolic heart failure (HF) is frequently accompanied by diastolic dysfunction and sleep-disordered breathing (SDB). Objectives: The objective of this subset analysis was to determine effect sizes of auto-servo ventilation (ASV and biphasic positive airway pressure ASV) on echocardiographic measures of diastolic function in patients with systolic HF and SDB. Methods: Thirty-two patients with stable systolic HF, concomitant diastolic dysfunction [age $66 \pm 9$ years old, left ventricular (LV) ejection fraction: $30 \pm$ $7 \%$ and New York Heart Association class II: 72\%] and SDB (apnea-hypopnea index, AHI: $48 \pm 19 / \mathrm{h} ; 53 \%$ had predominantly obstructive sleep apnea) receiving either ASV $(n=19)$ or optimal medical treatment (control, $n=13$ ) were analyzed in a randomized controlled clinical trial. Polysomnographic and echocardiographic measurements were obtained at baseline and after 12 weeks. Results: AHI significantly im-
\end{abstract}

\section{KARGER}

E-Mail karger@karger.com

www.karger.com/res proved in the ASV group compared to the control group $(-39 \pm 18$ vs. $-0.2 \pm 13.2 / \mathrm{h}, \mathrm{p}<0.001)$. At baseline, $24(75 \%)$ patients had impaired LV relaxation, and $8(25 \%)$ had a pseudo-normalized filling pattern. At the 12-week control visit, diastolic function assessed by the isovolumetric relaxation time $(-10.3 \pm 26.1$ vs. $9.3 \pm 49.1, p=0.48)$ and deceleration time $(-43.9 \pm 88.8$ vs. $12.4 \pm 68.8, p=0.40)$ tended to improve after ASV treatment, but did not reach statistical significance. Likewise, the proportion of patients whose diastolic dysfunction improved was nonsignificantly higher in the ASV than in the control group, respectively ( 37 vs. $15 \%, p=$ 0.25). Conclusions: ASV treatment efficiently abolishes SDB in patients with stable systolic HF and concomitant diastolic dysfunction, and was associated with a statistically nonsignificant improvement in measures of diastolic dysfunction. Thus, these data provide estimates of effect size and justify the evaluation of the effects of ASV on diastolic function in larger randomized controlled trials.

Copyright @ 2013 S. Karger AG, Basel

This paper contains parts of the MD thesis of S. Wunderlich.
(C) 2013 S. Karger AG, Basel

0025-7931/13/0871-0054\$38.00/0
Dr. Christoph Birner

Department of Internal Medicine II

University Hospital Regensburg

DE-93053 Regensburg (Germany)

E-Mail christoph.birner@ klinik.uni-regensburg.de 


\section{Introduction}

Heart failure (HF), affecting about $1-2 \%$ of individuals in the Western World with increasing prevalence with increasing age, is still associated with high morbidity and mortality [1]. Systolic left ventricular (LV) impairment, a hallmark of HF with reduced ejection fraction (HFREF), is often accompanied by diastolic dysfunction, which has been shown to represent an independent prognostic factor for a worse outcome - even in patients with concomitant systolic dysfunction [2-4]. Beyond that, accumulating evidence links HFREF to sleep-disordered breathing (SDB) as further concomitant entity, affecting about 51$76 \%$ of patients with HFREF [5-7].

Current pathophysiological concepts indicate that both HFREF and SDB stand in a reciprocal relationship with each other. While impaired cardiac function can cause and aggravate SDB [8], SDB may contribute to worsening of HFREF by increasing cardiac afterload, causing hypertension and myocardial hypertrophy [6,9-14].

In this context, facing the somehow stagnating therapeutic options in HFREF treatment [15], it has been hypothesized that an SDB-specific therapy might also be effective in improving parameters of cardiac dysfunction. In HF patients with impaired systolic function, there is robust evidence that continuous positive airway pressure (CPAP) modestly increases LV ejection fraction (LVEF). However, current evidence in such patients is conflicting with studies of auto-servo ventilation (ASV) showing a modest improvement in LVEF [16], whereas others did not $[17,18]$.

Furthermore, the effects of positive airway pressure treatment on diastolic dysfunction have not been studied in detail. A randomized crossover study in patients with SDB without evidence of HF showed that CPAP modestly improves echocardiographic parameters of diastolic dysfunction [19]. Another trial investigating ASV therapy in patients with SDB and concomitant HF with normal EF likewise found a moderate improvement in echocardiographic diastolic parameters [20]. However, there is no randomized controlled study evaluating the extent to which an SDB-specific therapy might influence diastolic dysfunction in patients with HFREF.

We therefore tested in a subset of patients with HFREF and SDB with concomitant diastolic dysfunction from a multicenter, randomized, rater-blinded, open label, parallel group trial [21] to which extent an SDB-specific therapy (ASV, biphasic PAP ASV, Philips Respironics) influences echocardiographic measures of LV structure and diastolic function compared to an optimal medical therapy alone.

\section{Patients and Methods}

\section{Patients}

The patient population analyzed is a subset of the multicenter, randomized, rater-blinded, open label, parallel group trial 'Treatment of Sleep-Disordered Breathing with Auto-Servo Ventilation in Congestive Heart Failure', which has been registered at http:// www.clinicaltrials.gov/ (ISRCTN04353156) [21].

Individuals were eligible to be part of the present analysis if they were 18-80 years old, had chronic HF due to ischemic or nonischemic cardiomyopathy, had a LVEF $\leq 40 \%$ on echocardiography, were in a stable clinical status (New York Heart Association class II or III) with optimal medical treatment according to the guidelines of the European Society of Cardiology [22] for at least 4 weeks and had an apnea-hypopnea index (AHI) $\geq 20 / \mathrm{h}$ sleep as assessed by in-laboratory polysomnography. Subjects were excluded if they had evidence of an unstable clinical status (unstable angina, myocardial infarction, cardiac surgery or hospital admission within the previous 3 months), had contraindications to PAP therapy, were on oxygen therapy, or had severe restrictive or obstructive airway disease. All patients gave written informed consent, and the protocol was approved by the local ethics boards of the participating institutions.

Eligible patients meeting all inclusion criteria were then assigned to either an ASV-treated group receiving ASV in addition to an optimal medical treatment for HF or a control group with optimal medical treatment alone. Echocardiographic (evaluation of systolic/diastolic function and LV diameters), hemodynamic (systolic and diastolic blood pressure, BP), neurohumoral [N-terminal (NT)-pro-B-type natriuretic peptide (BNP)] and SDB parameters (AHI) were determined at baseline and after 12 weeks, respectively.

Additional inclusion criteria for the present analysis were that echocardiographic parameters of diastolic dysfunction were available and that individuals fulfilled echocardiographic criteria for diastolic dysfunction (classified as either impaired relaxation, or pseudo-normal or restrictive filling pattern). These additional criteria applied to $44 \%$ of the initially included study cohort representing all subjects with a complete echocardiographic evaluation of diastolic dysfunction, which has been performed in two of four study centers (see fig. 1 for patient flow).

\section{Initiation of ASV}

By protocol, nighttime pressure settings had to be within the range of tolerated pressure settings during an attended daytime titration with monitoring of $\mathrm{BP}$ and heart rate (HR). During the first night, $\mathrm{CPAP}$ was titrated under polysomnographic monitoring from $4 \mathrm{~cm} \mathrm{H}_{2} \mathrm{O}$ in $1-\mathrm{cm} \mathrm{H}_{2} \mathrm{O}$ increments to the point where any sign of flow limitation was eliminated or the maximum level the patient could tolerate $\left(\leq 10 \mathrm{~cm} \mathrm{H}_{2} \mathrm{O}\right)$.

Before initiating ASV at night, a daytime titration with bilevel PAP was performed in order to avoid long-term application of ASV with pressure settings that may lead to hemodynamic compromise. First baseline BP and HR were recorded as described. Expiratory PAP was set at the optimal CPAP level suppressing upper airway obstruction determined by polysomnography. Inspiratory pressure support was titrated starting from $1 \mathrm{~cm} \mathrm{H}_{2} \mathrm{O}$ and increased by $1-\mathrm{cm} \mathrm{H}_{2} \mathrm{O}$ up to the maximum of $10 \mathrm{~cm} \mathrm{H}_{2} \mathrm{O}$ every 5 min after BP and HR reading was taken. Attended daytime inspiratory pressure support titration was stopped when a pressure 


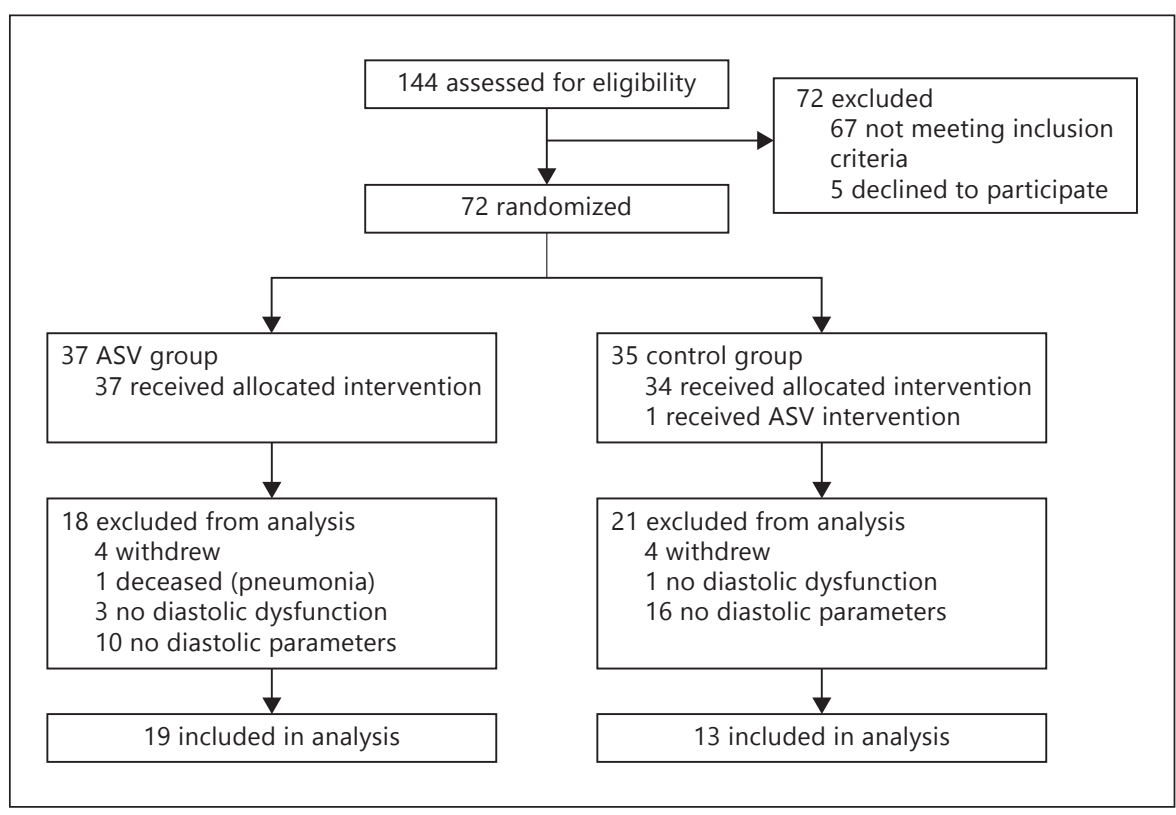

Fig. 1. Study protocol.

of $10 \mathrm{~cm} \mathrm{H} \mathrm{H}_{2} \mathrm{O}$ was reached or if mean $\mathrm{BP}<60 \mathrm{~mm} \mathrm{Hg}$ or a drop of $>15 \mathrm{~mm} \mathrm{Hg}$ occurred or the patient did not tolerate inspiratory pressure support.

At the ASV initiation night, the expiratory PAP of the ASV device was set to the CPAP determined during the titration night. The minimum inspiratory PAP was set to the expiratory PAP level, and the maximum inspiratory PAP to a maximum of $10 \mathrm{~cm} \mathrm{H}_{2} \mathrm{O}$ above the expiratory PAP level, or not higher than the maximum the patient could tolerate during the daytime test. The default backup rate of the machine was used. Assessment of hours of ASV use over this period were obtained from the downloadable SmartCard located in the device.

\section{Echocardiography}

Transthoracic echocardiography was performed with patients in the supine and left-lateral positions using high-quality echocardiographs. Images were obtained in the parasternal long- and short-axis, apical 2- and 4-chamber, and subcostal views with $2 \mathrm{D}, \mathrm{M}$-mode and Doppler echocardiography. Investigators were experienced echocardiographers, and each echocardiogram was centralized to two blinded analysts. Left atrial diameter, LV end-diastolic and end-systolic diameters, as well as interventricular septum thickness and LV posterior wall thickness were determined in accordance with the recommendations of the American Society of Echocardiography [23]. LV systolic function was assessed by LVEF obtained by the Simpson's method (LV end-diastolic volume minus LV end-systolic volume divided by end-diastolic volume). LV mass (LVM) was calculated from M-mode echocardiograms according to the formula described by Devereux et al. [24], and LVM index (LVMI) was obtained by indexing LVM to body surface area. Relative wall thickness was determined by the formula $(2 \times$ PWTd $) / L V I D d$, where PWTd is posterior wall thickness at end-diastole and LVIDd is end-diastolic ventricular internal dimension at enddiastole [23].
LV diastolic function was assessed by measuring the mitral inflow pattern (with the sample volume placed between the leaflet tips using pulsed-wave Doppler technique), the deceleration time (DT) and the isovolumetric relaxation time (IVRT). Peak flow velocity in early diastole (E wave) was divided by the peak velocity at atrial contraction (A wave) resulting in the E/A ratio. LV filling patterns were then classified as normal, impaired relaxation, pseudo-normal or restrictive. A normal pattern was defined by E/A ratio $>1$, and normal DT $(<220 \mathrm{~ms})$ and IVRT $(<100 \mathrm{~ms})$. Impaired relaxation was identified by E/A ratio $<1$, DT $>220 \mathrm{~ms}$ and IVRT $>100$ ms. A pseudo-normal pattern was determined by E/A ratio ranging from 1 to $1.5, \mathrm{DT}<150 \mathrm{~ms}$ and IVRT $<60 \mathrm{~ms}$, and a restrictive pattern was defined by E/A ratio $>1.5, \mathrm{DT}<150 \mathrm{~ms}$ and IVRT $<60 \mathrm{~ms}$ [25].

\section{Statistical Analysis}

Values are expressed as means \pm SD or percentages. Baseline characteristics of the patients in the two groups were compared using the nonparametric Wilcoxon-Mann-Whitney test. To take into account potential differences in baseline rates between the two groups, we used a generalized linear model based on ranks (nonparametric) with the respective baseline value as covariate. All statistical tests were two sided with a significance level of $5 \%$. All statistical tests were performed with SPSS 20.0.

\section{Results}

\section{Patient Characteristics}

In the initial study cohort (participating patients with complete assessment of diastolic function; fig. 1), the prevalence of diastolic dysfunction was very high (86 and $93 \%$ in the treatment and control group, respectively). 
Table 1. Baseline characteristics of the study patients

\begin{tabular}{|c|c|c|c|}
\hline & ASV & Control & $\mathrm{p}$ value \\
\hline Patients, $\mathrm{n}$ & 19 & 13 & \\
\hline Age, years & $66 \pm 9$ & $66 \pm 11$ & 0.73 \\
\hline Males, $\mathrm{n}(\%)$ & $18(95)$ & $11(85)$ & 0.55 \\
\hline Body mass index, $\mathrm{kg} / \mathrm{m}^{2}$ & $29.9 \pm 4.0$ & $30.7 \pm 3.6$ & 0.58 \\
\hline Smokers, n (\%) & $2(11)$ & $3(23)$ & 0.16 \\
\hline \multicolumn{4}{|l|}{$\mathrm{BP}, \mathrm{mm} \mathrm{Hg}$} \\
\hline Systolic & $120 \pm 18$ & $128 \pm 24$ & 0.40 \\
\hline Diastolic & $70 \pm 14$ & $75 \pm 11$ & 0.37 \\
\hline Heart rate, b.p.m. & $70 \pm 10$ & $71 \pm 12$ & 0.64 \\
\hline \multicolumn{3}{|c|}{ New York Heart Association class, n (\%) ${ }^{1}$} & 0.35 \\
\hline II & $12(63)$ & $11(85)$ & \\
\hline III & $5(26)$ & $1(8)$ & \\
\hline LVEF, $\%$ & $30 \pm 8$ & $29 \pm 7$ & 0.66 \\
\hline NT-pro-BNP, ng/ml & $1,046 \pm 1,195$ & $997 \pm 1,344$ & 0.33 \\
\hline Cause of HF, n (\%) & & & 0.47 \\
\hline Ischemic & $9(47)$ & $6(46)$ & \\
\hline Nonischemic & $10(53)$ & $7(54)$ & \\
\hline Sleep apnea, n (\%) & & & 1.00 \\
\hline Obstructive & $10(53)$ & $7(54)$ & \\
\hline Central & $9(47)$ & $6(46)$ & \\
\hline AHI, events/h & $51.7 \pm 18.9$ & $43.1 \pm 18.4$ & 0.33 \\
\hline \multicolumn{4}{|l|}{ Medication, n (\%) } \\
\hline Diuretic & $11(58)$ & $11(85)$ & 0.14 \\
\hline Spironolactone & $9(47)$ & $8(62)$ & 0.49 \\
\hline ACEI & $15(79)$ & $9(69)$ & 0.68 \\
\hline $\mathrm{ARB}$ & $4(21)$ & $5(38)$ & 0.43 \\
\hline$\beta$-Blocker & $16(84)$ & $13(100)$ & 0.25 \\
\hline
\end{tabular}

ACEI = Angiotensin-converting enzyme inhibitor; $\mathrm{ARB}=$ angiotensin receptor blocker.

${ }^{1}$ Data of 2 and 1 patients are missing in the ASV and control group, respectively.

Patients with diastolic dysfunction were predominantly normotensive males with both ischemic and nonischemic systolic HF (mainly New York Heart Association class II congestive HF severity) and concomitant obstructive or central sleep apnea indicated by a pathological AHI. Medical therapy was sufficient according to current guidelines with a high percentage of patients treated with $\beta$-blockers, angiotensin-converting enzyme inhibitors or angiotensin receptor blockers, and spironolactone. Table 1 shows the proportion of patients using cardiac medication, which did not change significantly during the follow-up period: in 1 patient from the control group, a $\beta$-blocker was added, and in 2 patients from the ASV group spironolactone was discontinued.

There were no statistically significant differences between both groups in demographic, hemodynamic, echocardiographic or SDB parameters.

\section{SDB Parameters}

At baseline, AHI was $51.7 \pm 18.9$ events/h in the ASVallocated group and $43.1 \pm 18.4$ events/h in the control group ( $\mathrm{p}=0.33$ ). After 12 weeks of ASV treatment, AHI was significantly reduced to $11.2 \pm 7.2$ events/h, whereas it remained unchanged in the control group $(\mathrm{p}<0.001$ ASV vs. control; table 2). The average daily ASV use during the study period was $4.2 \pm 2.7 \mathrm{~h}$.

\section{Hemodynamic, Neurohumoral and Functional LV \\ Parameters}

Individuals of both groups were normotensive at baseline, and neither systolic nor diastolic BP did vary significantly after 12 weeks (table 2). Likewise, NT-pro-BNP levels were similar in both groups at baseline, showing no significant difference after 12 weeks (table 2). Baseline LV systolic function measured by LVEF was $30 \pm 8 \%$ in the ASV group and $29 \pm 7 \%$ in the control group $(\mathrm{p}=0.66)$. After 12 weeks, the change in LVEF was similar in the ASV-treated and control groups $(p=0.75$, table 2$)$.

\section{Structural Parameters}

LV structural parameters were largely unchanged during the 12-week follow-up of both the ASV and the control group. Relative wall thickness was unchanged in the treatment group but tended to increase in control subjects.

\section{Parameters of Diastolic LV Dysfunction}

Severity of diastolic dysfunction was graded according to echocardiographic measurements of the E/A ratio, DT and IVRT. At baseline, most patients had impaired LV relaxation (i.e. grade 1 diastolic dysfunction), and about one quarter revealed a pseudo-normal filling pattern (fig. 2a). After 12 weeks, more ASV than control patients improved to a normal filling pattern (26 vs. $15 \%$ ), and less ASV than control patients remained in the pseudo-normal state (11 vs. $23 \%$ ), even though neither of these ASVmediated improvements reached statistical significance $(\mathrm{p}=0.55$; fig. $2 \mathrm{~b})$. Regarding the individual parameters of diastolic dysfunction, the E/A ratio slightly increased in both study groups (fig. 3a).

In the ASV group, DT and IVRT were reduced, indicating improvement in diastolic function, while in the control group DT remained similar within the follow-up period. Between-group differences comparing the change in DT and IVRT within 12 weeks were statistically not significant $(\mathrm{p}=0.40$ and $\mathrm{p}=0.48$, respectively; table 2 ; figure $3 b, c)$. 


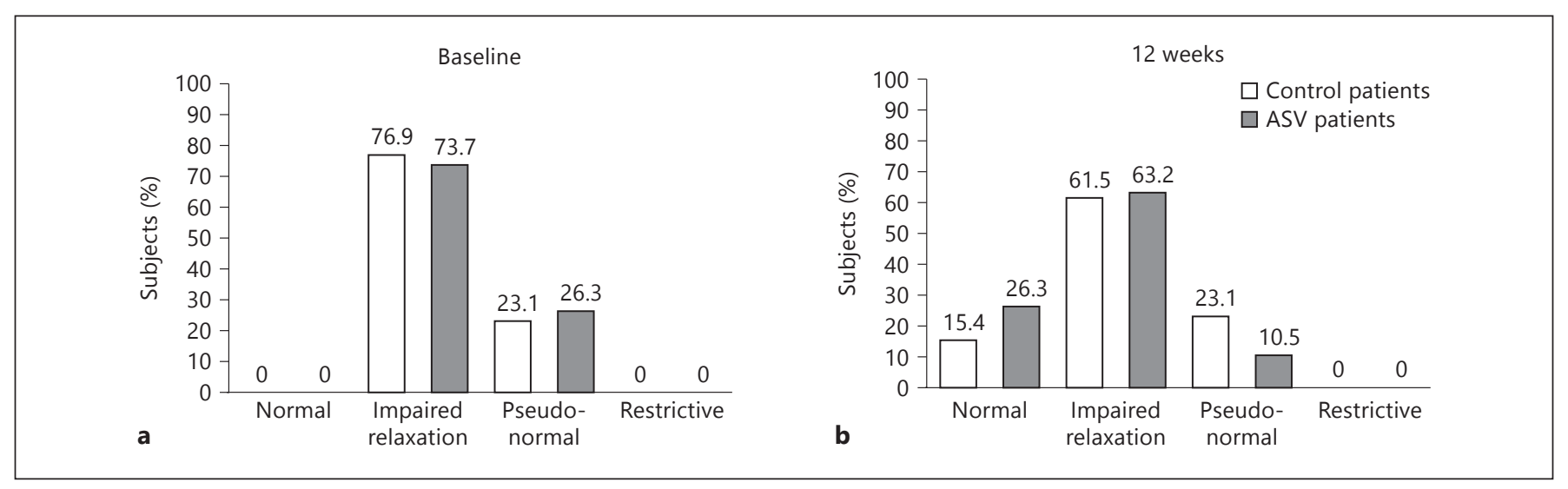

Fig. 2. Grade of diastolic dysfunction at baseline (a) and after 12 weeks (b) in ASV (gray bars) and control subjects (white bars).

Table 2. Sleep, neurohumoral and echocardiographic parameters and blood pressure in ASV versus control patients at baseline and after 12 weeks

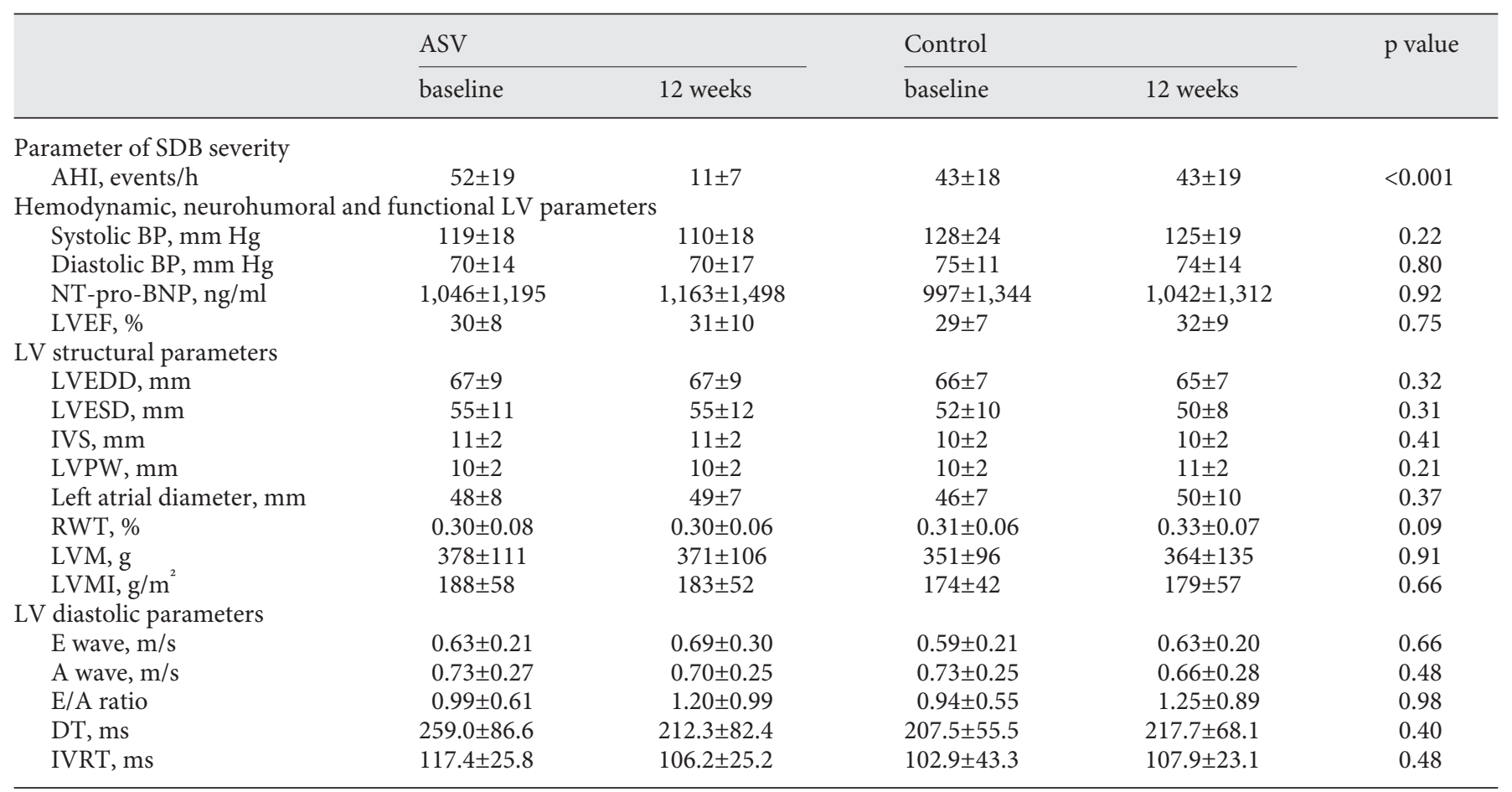

LVEDD = LV end-diastolic diameter; LVESD = LV end-systolic diameter; IVS = interventricular septum thickness; LVPW = LV posterior wall thickness; RWT = relative wall thickness. To be able to take potential differences in baseline rates between the two groups into account, a generalized linear model based on ranks (nonparametric) with the respective baseline value as covariate was used.

\section{Discussion}

The main findings of this study evaluating ASV therapy in patients with HFREF, diastolic dysfunction and SDB are that (1) prevalence of diastolic dysfunction is very high in patients with HFREF and SDB; (2) ASV therapy effectively suppresses SDB, and (3) ASV therapy does not significantly alter echocardiographic measures of LV structure and diastolic dysfunction in this study cohort. 
Prevalence of LV Diastolic Dysfunction

Diastolic dysfunction was detected in a total of $89 \%$ of patients with HFREF in the current analysis, which is similar to the $82 \%$ prevalence reported in larger samples of HFREF patients from the community [26]. A previous study in patients with normal EF observed a close relationship between SDB and diastolic dysfunction affecting 23 [27] to 56\% [19] of subjects under investigation with a stepwise further increase as severity of SDB rises, ultimately reaching a prevalence of approximately $70 \%$ [28]. Even though this link between SDB and diastolic dysfunction is evident, the underlying pathophysiological mechanisms are still not well characterized. It has been hypothesized that both elevations in nocturnal BP and activation of the sympathetic nervous system might contribute to this effect [2931] by increasing LV afterload [32]. Furthermore, futile inspiratory efforts hallmarking obstructive sleep apnea might increase LV transmural pressure and hence afterload by inducing negative intrathoracic pressures [32], ultimately provoking diastolic dysfunction. Even though each of these concepts could plausibly explain the impact of SDB on diastolic dysfunction on its own, any deterioration in diastolic filling in patients with advanced complex disease, such as severely impaired cardiac function, might most likely be caused polyetiologically.

\section{Effectiveness of ASV Therapy on SDB Severity and LV} Systolic Dysfunction

In accordance with previous studies, ASV therapy was highly efficient in suppressing apnea and hypopnea in patients with SDB and HF [16, 17, 33-38].

In contrast, LV systolic function determined by EF did not significantly improve in ASV-treated patients. On the one hand, this is congruent with previous findings, which also did not reveal a significant effect of an SDB-specific therapy on LVEF in HF patients $[17,39]$ but, on the other hand, it contrasts with studies reporting a positive effect on systolic function [16, 36, 38, 40-43]. For instance, Bradley et al. [40] described a rather moderate but significant gain of systolic function (LVEF $2.2 \pm 5.4$ vs. $0.4 \pm$ $5.3 \%, \mathrm{p}=0.02$ ) in their study evaluating CPAP versus no CPAP in $258 \mathrm{HF}$ patients with central sleep apnea. This discrepancy between trials showing positive effects of an SDB-specific therapy on LVEF and studies, e.g. ours, which could not find such a relationship, could have two main reasons. First, improvements in LVEF might depend on the duration of SDB-specific therapy. This is supported by the finding that trials with a treatment du-

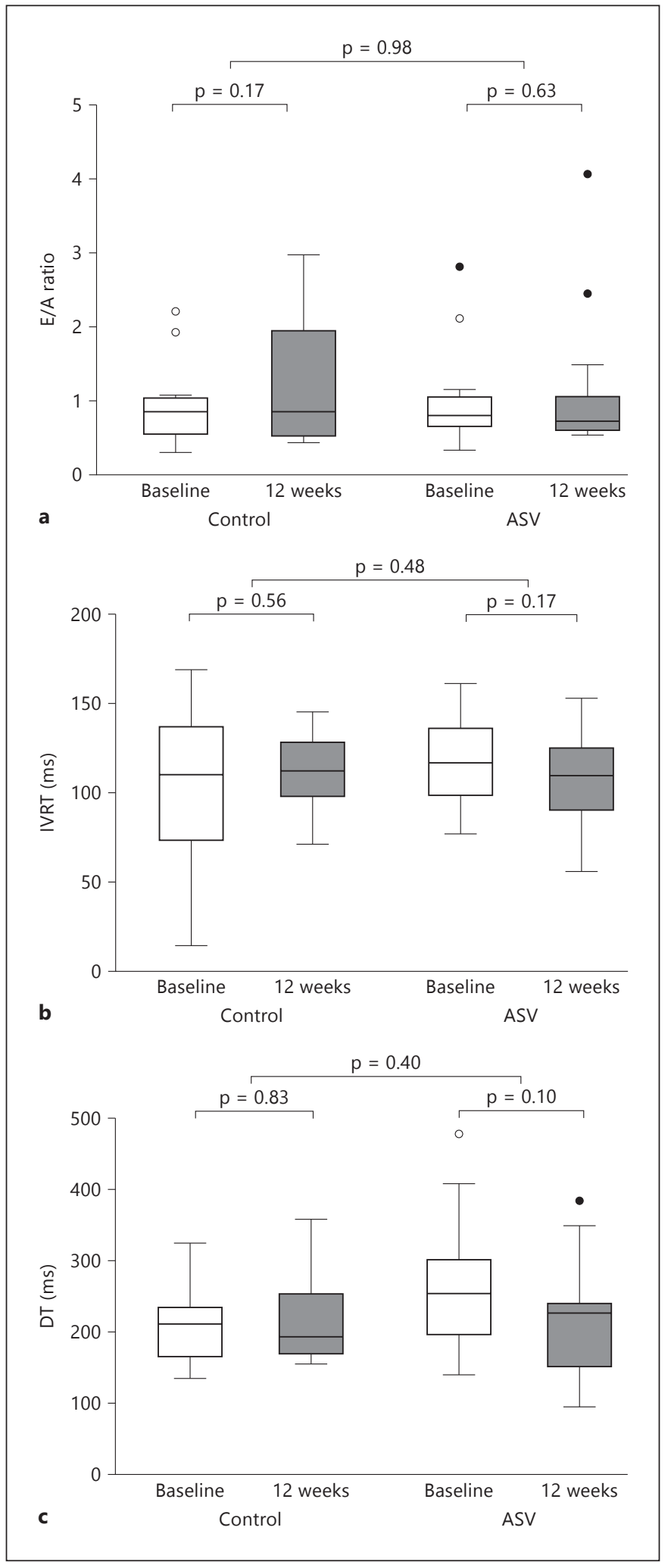

Fig. 3. E/A ratio (a), IVRT (b) and DT (c) in ASV-treated (right) versus control subjects (left) at baseline (white bars) and after 12 weeks (gray bars). 
ration $\leq 6$ weeks could not show a significant effect of ASV on LVEF $[17,18]$, whereas studies with a treatment duration $>6$ weeks did $[36,38]$. This time dependency was also found in trials evaluating acute versus chronic effects of an SDB-specific therapy: so LVEF was even significantly reduced after acute initiation of CPAP treatment and only improved with ongoing therapy eventually leading to a significant gain of LVEF in the longer term $[44,45]$. Secondly, since treatment effects on LVEF are generally rather low (as seen by a $2.2 \pm 5.4 \%$ improvement in LVEF in the 258 patients evaluated by Bradley et al. [40]), the cohort size under investigation might also be of relevance, and larger cohorts need to be evaluated to finally judge the impact of ASV therapy on LVEF.

\section{Impact of ASV Therapy on Diastolic Dysfunction and} LV Geometry

Our study was the largest one to evaluate echocardiographic parameters of LV diastolic dysfunction in a collective of HFREF patients with concomitant sleep apnea. Even though there was no significant overall change in diastolic dysfunction, we nevertheless found a modest decrease in both DT and IVRT in the ASV-treated group with opposite changes in the control group. These moderate alterations translated into more patients in the ASV-treated group reaching a normal diastolic function with less patients remaining in the state of a pseudo-normal filling pattern than control patients, respectively. As for the systolic LV function, treatment duration might again be a determinant of effect size, which means that longer treatment periods could eventually unveil more distinct changes in LV diastolic function. This is supported by Bitter et al. [20], who evaluated ASV treatment in patients with $\mathrm{HF}$ and normal EF. In this trial, echocardiographic parameters of diastolic dysfunction improved after a time period of $11.6 \pm 3$ months. In contrast, Arias et al. [19], investigating the impact of ASV treatment on diastolic function in individuals with obstructive sleep apnea, but no concomitant cardiac disease, found an improvement in echocardiographic parameters already after a mean of $104 \pm 31$ days, with effect sizes which were rather similar to the ones found in our study. This in mind, it seems plausible that ASV treatment needs to be executed the longer the more severely cardiac function is impaired to eventually improve also diastolic dysfunction.

Patients included in the current analysis displayed a pronounced eccentric LV hypertrophy indicated by a relatively low LV wall thickness and a high LVMI. Even though it did not reach statistical significance, LVMI tended to decrease in the ASV treatment group and to further increase in the control group after 12 weeks, respectively.

Interestingly, it has been shown that LVMI is positively correlated with the severity of sleep apnea in patients with both normal [46] and impaired systolic LV function [47]. Furthermore, CPAP therapy proved to be efficient in reducing LVM in a cohort of patients with normal EF [48]. Sleep apnea seems to further aggravate structural LV anomaly even in HFREF patients, and an SDB-specific therapy has the potential to reverse pathological LV remodeling. Against this background, it seems plausible that subjects suffering from severely impaired cardiac function, as the ones included in the current analysis, might need SDB therapy for a longer period than 12 weeks to more explicitly exhibit reverse cardiac remodeling. This is also supported by the work from Colish et al. [48], who found an ongoing decrease in LVMI even after 12 months of CPAP therapy in patients without LV systolic dysfunction.

Regarding other measures of LV geometry, Kaneko et al. [49] observed in a single-center randomized controlled trial of similar sample size in patients with congestive HF and obstructive sleep apnea a significant reduction of LV end-systolic diameter after 4 weeks of CPAP treatment versus control. In the present multicenter study in patients with congestive HF on contemporary HF therapy with both obstructive and central sleep apnea, ASV therapy had no significant effects on LV diameters.

\section{Limitations}

The number of study patients was limited, since this subset analysis was conceptually intended as pilot trial to provide estimates of effect size to be expected. Otherwise, this investigation is the largest one to date which analyzed effects of ASV therapy on diastolic dysfunction in HFREF patients.

Furthermore, since randomization of the initial study cohort was stratified by study center and type of SDB (i.e. central and obstructive sleep apnea), every subset analysis might alter this initial randomization and stratification scheme. However, the proportion of patients from each center included in the present analysis was similar in the ASV and control groups, respectively, and the proportion of patients with predominantly obstructive sleep apnea was similar in the primary analysis [50] and in the present analysis (ASV group: 47 vs. 53\%; control group: 52 vs. $54 \%)$. Thus, it is unlikely that the present subgroup analysis of ASV and control patients significantly altered the
Birner et al. 
original randomization or stratification scheme, leading to a false-positive result.

Finally, there might have been additional confounders influencing the effects of ASV therapy on diastolic function, such as a change in medication or compliance to use ASV during the study period. We therefore additionally adjusted for these parameters, which resulted in a significant decrease in NT-pro-BNP in the ASV group after 12 weeks compared to control patients $(\mathrm{p}=0.009)$, whereas there was no significant alteration in any structural or functional (systolic and diastolic) LV parameter (data not shown).

\section{Conclusion}

The current study revealed a high prevalence of diastolic dysfunction in patients with HFREF and concomitant sleep apnea. It furthermore confirmed the efficiency of ASV in reducing apnea-hypopnea events in SDB patients. Whereas neither systolic nor diastolic parameters significantly changed after ASV therapy, there were nevertheless trends towards an improvement in both diastolic function and cardiac remodeling. Thus, these data pro- vide estimates of effect size and justify the evaluation of the effects of ASV on diastolic function in larger randomized controlled trials.

\section{Financial Disclosure and Conflict of Interest}

This work was supported by a grant from Philips Home Healthcare Solutions (Murrysville, Pa., USA). The sponsor played no role in the design, conduct of the study as well as analysis and interpretation of the data. The sponsor played no role in the preparation, review and approval of the paper.

Michael Arzt has received grant support from Philips Home Healthcare Solutions, Resmed (Martinsried, Germany) and the German Foundation for Cardiac Research (Deutsche Stiftung für Herzforschung). He is the holder of an endowed professorship from the Free State of Bavaria at the University of Regensburg that was donated by Philips Home Healthcare Solutions and Resmed. Michael Arzt has previously received lecture fees from AstraZeneca, Covidien, Philips Home Healthcare Solutions and Resmed. Keir Lewis has received grant support from Pfizer Inc., and lecture fees and reimbursement for attending conferences from Pfizer, AstraZeneca and Glaxo-Smith Kline. He has participated in advisory boards for MSD, AstraZeneca and Glaxo-Smith Kline. Christoph Birner, Silke Wunderlich and Michael Arzt had full access to all of the data in the study and take responsibility for the integrity of the data and the accuracy of the data analysis.

\section{References}

1 Mosterd A, Hoes AW: Clinical epidemiology of heart failure. Heart 2007;93:1137-1146.

2 Giannuzzi P, Temporelli PL, Bosimini E, Silva $\mathrm{P}$, Imparato $\mathrm{A}$, Corrà $\mathrm{U}$, et al: Independent and incremental prognostic value of Dopplerderived mitral deceleration time of early filling in both symptomatic and asymptomatic patients with left ventricular dysfunction. J Am Coll Cardiol 1996;28:383-390.

-3 Hansen A, Haass M, Zugck C, Krueger C, Unnebrink K, Zimmermann R, et al: Prognostic value of Doppler echocardiographic mitral inflow patterns: implications for risk stratification in patients with chronic congestive heart failure. J Am Coll Cardiol 2001;37:1049-1055.

4 Pinamonti B, Di Lenarda A, Sinagra G, Camerini F: Restrictive left ventricular filling pattern in dilated cardiomyopathy assessed by Doppler echocardiography: clinical, echocardiographic and hemodynamic correlations and prognostic implications. Heart Muscle Disease Study Group. J Am Coll Cardiol 1993; 22:808-815.

5 Javaheri S, Parker TJ, Liming JD, Corbett WS, Nishiyama H, Wexler L, et al: Sleep apnea in 81 ambulatory male patients with stable heart failure. Types and their prevalences, consequences, and presentations. Circulation 1998; 97:2154-2159.
-6 Lanfranchi PA, Braghiroli A, Bosimini E, Mazzuero G, Colombo R, Donner CF, et al: Prognostic value of nocturnal Cheyne-Stokes respiration in chronic heart failure. Circulation 1999;99:1435-1440.

7 Oldenburg O, Lamp B, Faber L, Teschler H, Horstkotte D, Töpfer V: Sleep-disordered breathing in patients with symptomatic heart failure: a contemporary study of prevalence in and characteristics of 700 patients. Eur J Heart Fail 2007;9:251-257.

8 Solin P, Bergin P, Richardson M, Kaye DM, Walters EH, Naughton MT: Influence of pulmonary capillary wedge pressure on central apnea in heart failure. Circulation 1999;99:1574-1579.

-9 Becker HF, Jerrentrup A, Ploch T, Grote L, Penzel T, Sullivan CE, et al: Effect of nasal continuous positive airway pressure treatment on blood pressure in patients with obstructive sleep apnea. Circulation 2003;107:68-73.

10 Shivalkar B, van de Heyning C, Kerremans M, Rinkevich D, Verbraecken J, de Backer W, et al: Obstructive sleep apnea syndrome: more insights on structural and functional cardiac alterations, and the effects of treatment with continuous positive airway pressure. J Am Coll Cardiol 2006;47:1433-1439.

-11 Jaffe LM, Kjekshus J, Gottlieb SS: Importance and management of chronic sleep ap- noea in cardiology. Eur Heart J 2013;34: 809-815.

12 Jilek C, Krenn M, Sebah D, Obermeier R, Braune A, Kehl V, et al: Prognostic impact of sleep disordered breathing and its treatment in heart failure: an observational study. Eur J Heart Fail 2011;13:68-75.

13 Buchner S, Greimel T, Hetzenecker A, Luchner A, Hamer OW, Debl K, et al: Natural course of sleep-disordered breathing after acute myocardial infarction. Eur Respir J 2012;40:1173-1179.

14 Bitter T, Westerheide N, Prinz C, Hossain MS, Vogt J, Langer C, et al: Cheyne-Stokes respiration and obstructive sleep apnoea are independent risk factors for malignant ventricular arrhythmias requiring appropriate cardioverterdefibrillator therapies in patients with congestive heart failure. Eur Heart J 2011;32:61-74.

15 Brutsaert DL: Cardiac failure: quo vadis? Eur J Heart Fail 2010;12:785-788.

16 Kasai T, Usui Y, Yoshioka T, Yanagisawa N, Takata Y, Narui K, et al: Effect of flow-triggered adaptive servo-ventilation compared with continuous positive airway pressure in patients with chronic heart failure with coexisting obstructive sleep apnea and CheyneStokes respiration. Circ Heart Fail 2010;3: 140-148. 
17 Fietze I, Blau A, Glos M, Theres H, Baumann G, Penzel T: Bi-level positive pressure ventilation and adaptive servo ventilation in patients with heart failure and CheyneStokes respiration. Sleep Med 2008;9:652659.

18 Pepperell JCT, Maskell NA, Jones DR, Langford-Wiley BA, Crosthwaite N, Stradling JR, et al: A randomized controlled trial of adaptive ventilation for Cheyne-Stokes breathing in heart failure. Am J Respir Crit Care Med 2003;168:1109-1114.

-19 Arias MA, García-Río F, Alonso-Fernández A, Mediano O, Martínez I, Villamor J: Obstructive sleep apnea syndrome affects left ventricular diastolic function: effects of nasal continuous positive airway pressure in men. Circulation 2005;112:375-383.

-20 Bitter T, Westerheide N, Faber L, Hering D, Prinz C, Langer C, et al: Adaptive servoventilation in diastolic heart failure and CheyneStokes respiration. Eur Respir J 2010;36:385392.

21 Arzt M, Series F, Lewis K, Escourrou P, Obermeier R, Kehl V, et al: Effects of auto-servo ventilation on cardiovascular function in patients with congestive heart failure and sleepdisordered breathing - a multicenter randomised controlled trial. Eur Respir J 2011; 38(suppl 55):P1743.

-22 Dickstein K, Cohen-Solal A, Filippatos G, McMurray JJV, Ponikowski P, Poole-Wilson $\mathrm{PA}$, et al: ESC guidelines for the diagnosis and treatment of acute and chronic heart failure 2008: the Task Force for the diagnosis and treatment of acute and chronic heart failure 2008 of the European Society of Cardiology. Developed in collaboration with the Heart Failure Association of the ESC (HFA) and endorsed by the European Society of Intensive Care Medicine (ESICM). Eur J Heart Fail 2008;10:933-989.

23 Lang RM, Bierig M, Devereux RB, Flachskampf FA, Foster E, Pellikka PA, et al: Recommendations for chamber quantification: a report from the American Society of Echocardiography's Guidelines and Standards Committee and the Chamber Quantification Writing Group, developed in conjunction with the European Association of Echocardiography, a branch of the European Society of Cardiology. J Am Soc Echocardiogr 2005; 18:1440-1463.

-24 Devereux RB, Koren MJ, de Simone G, Okin PM, Kligfield P: Methods for detection of left ventricular hypertrophy: application to hypertensive heart disease. Eur Heart J 1993;14: 8-15.

25 Voelker W: Strukturierter Datensatz zur Befunddokumentation in der Echokardiographie - Version 2004 für den Arbeitskreis 'Standardisierung und LV-Funktion' der Arbeitsgruppe Kardiovaskulärer Ultraschall der DGK. Z Kardiol 2004;93:987-1004.
26 Bursi F, Weston SA, Redfield MM, Jacobsen SJ, Pakhomov S, Nkomo VT, et al: Systolic and diastolic heart failure in the community. JAMA 2006;296:2209-2216.

27 Baguet J, Barone-Rochette G, Lévy P, Vautrin E, Pierre H, Ormezzano O, et al: Left ventricular diastolic dysfunction is linked to severity of obstructive sleep apnoea. Eur Respir J 2010; 36:1323-1329.

28 Wachter R, Lüthje L, Klemmstein D, Lüers C, Stahrenberg R, Edelmann F, et al: Impact of obstructive sleep apnoea on diastolic function. Eur Respir J 2013;41:376-383.

29 Somers VK, Dyken ME, Clary MP, Abboud FM: Sympathetic neural mechanisms in obstructive sleep apnea. J Clin Invest 1995;96: 1897-1904.

30 Dincer HE, O'Neill W: Deleterious effects of sleep-disordered breathing on the heart and vascular system. Respiration 2006;73:124130.

31 Brack T, Randerath W, Bloch KE: CheyneStokes respiration in patients with heart failure: prevalence, causes, consequences and treatments. Respiration 2012;83:165-176.

32 Bradley TD, Hall MJ, Ando S, Floras JS: Hemodynamic effects of simulated obstructive apneas in humans with and without heart failure. Chest 2001;119:1827-1835.

33 Sharma BK, Bakker JP, McSharry DG, Desai AS, Javaheri S, Malhotra A: Adaptive servoventilation for treatment of sleep-disordered breathing in heart failure: a systematic review and meta-analysis. Chest 2012;142: 1211-1221.

34 Töpfer V, El-Sebai M, Wessendorf TE, Moraidis I, Teschler H: Adaptive Servoventilation bei chronischer Herzinsuffizienz: Wirkung auf Cheyne-Stokes-Atmung und Lebensqualität. Pneumologie 2004;58:28-32.

35 Randerath WJ, Galetke W, Kenter M, Richter $\mathrm{K}$, Schäfer T: Combined adaptive servo-ventilation and automatic positive airway pressure (anticyclic modulated ventilation) in coexisting obstructive and central sleep apnea syndrome and periodic breathing. Sleep Med 2009;10:898-903.

36 Philippe C, Stoïca-Herman M, Drouot X, Raffestin B, Escourrou P, Hittinger L, et al: Compliance with and effectiveness of adaptive servoventilation versus continuous positive airway pressure in the treatment of CheyneStokes respiration in heart failure over a six month period. Heart 2006;92:337-342.

37 Arzt M, Wensel R, Montalvan S, Schichtl T, Schroll S, Budweiser S, et al: Effects of dynamic bilevel positive airway pressure support on central sleep apnea in men with heart failure. Chest 2008;134:61-66.

38 Hastings PC, Vazir A, Meadows GE, Dayer M, Poole-Wilson PA, McIntyre HF, et al: Adaptive servo-ventilation in heart failure patients with sleep apnea: a real world study. Int J Cardiol 2010;139:17-24.
39 Randerath WJ, Nothofer G, Priegnitz C, Anduleit N, Treml M, Kehl V, et al: Long-term auto-servoventilation or constant positive pressure in heart failure and co-existing central with obstructive sleep apnea. Chest 2012; 142:440-447.

40 Bradley TD, Logan AG, Kimoff RJ, Sériès F, Morrison D, Ferguson K, et al: Continuous positive airway pressure for central sleep apnea and heart failure. N Engl J Med 2005;353: 2025-2033.

41 Koyama T, Watanabe H, Terada S, Makabe S, Igarashi G, Nobori K, et al: Adaptive servoventilation improves renal function in patients with heart failure. Respir Med 2011;105: 1946-1953.

42 Oldenburg O, Bitter T, Lehmann R, Korte S, Dimitriadis Z, Faber L, et al: Adaptive servoventilation improves cardiac function and respiratory stability. Clin Res Cardiol 2011; 100:107-115.

43 Steiner S, Schannwell CM, Strauer BE: Left ventricular response to continuous positive airway pressure: role of left ventricular geometry. Respiration 2008;76:393-397.

44 Johnson CB, Beanlands RS, Yoshinaga K, Haddad H, Leech J, de Kemp R, et al: Acute and chronic effects of continuous positive airway pressure therapy on left ventricular systolic and diastolic function in patients with obstructive sleep apnea and congestive heart failure. Can J Cardiol 2008;24:697-704.

45 Yoshinaga K, Burwash IG, Leech JA, Haddad $\mathrm{H}$, Johnson CB, de Kemp RA, et al: The effects of continuous positive airway pressure on myocardial energetics in patients with heart failure and obstructive sleep apnea. J Am Coll Cardiol 2007;49:450-458.

46 Dursunoglu D, Dursunoglu N, Evrengül H, Ozkurt S, Kuru O, Kiliç M, et al: Impact of obstructive sleep apnoea on left ventricular mass and global function. Eur Respir J 2005; 26:283-288.

47 Damy T, Paulino A, Margarit L, Drouot X, Stoica M, Vermes E, et al: Left ventricle remodelling is associated with sleep-disordered breathing in non-ischaemic cardiopathy with systolic dysfunction. J Sleep Res 2011;20:101-109.

48 Colish J, Walker JR, Elmayergi N, Almutairi S, Alharbi F, Lytwyn M, et al: Obstructive sleep apnea: effects of continuous positive airway pressure on cardiac remodeling as assessed by cardiac biomarkers, echocardiography, and cardiac MRI. Chest 2012;141:674-681.

49 Kaneko Y, Floras JS, Usui K, Plante J, Tkacova R, Kubo T, et al: Cardiovascular effects of continuous positive airway pressure in patients with heart failure and obstructive sleep apnea. N Engl J Med 2003;348:1233-1241.

50 Arzt M, Schroll S, Series F, Lewis K, Benjamin A, Escourrou P, et al: Auto-servo ventilation in heart failure with sleep apnea - a randomized controlled trial. Eur Respir J 2012, E-pub ahead of print. 